\title{
EL EQUILIBRIO DE LOS LÍMITES. CANTO AL TRABAJO, UN ESPECTÁCULO ETNOGRÁFICO CONVERTIDO EN LIBRO-CD.
}

\author{
Darío Hernández y Ciro R. Niebla Piñero \\ Universidad de La Laguna
}

El acompañamiento con canciones populares de las labores propias del campo, de la mar y del hogar es un hecho extendido desde tiempos inmemoriales y por múltiples culturas, en algunas de las cuales ha gozado el fenómeno, además, de un importante valor simbólico y ritual ${ }^{1}$. Convertir esta realidad histórica y antropológica en un hermoso espectáculo dramático-musical fue el objetivo del director de escena y percusionista canario Jonatan Rodríguez al coordinar el trabajo de los integrantes del grupo Pieles, compuesto por músicos, cantantes y actores, para la creación de Canto al trabajo, obra a través de la que se ha venido a reivindicar y a poner en valor la tradición folclórica de las Islas Canarias ${ }^{2}$ Y Y ello, precisamente, mediante la actualización de nuestros cantos vernáculos vinculados al trabajo y su fusión con sonidos de procedencias diversas: "Pieles

1. Este trabajo se enmarca dentro de los estudios llevados a cabo por el Grupo de Investigación "Palingestos. Fiesta y espectáculo en la cultura popular en su contexto atlántico: literatura, arte, cine y teatro", vinculado al Departamento de Filología Española de la Facultad de Humanidades de la Universidad de La Laguna, grupo coordinado por el Dr. José Antonio Ramos Arteaga.

2. Este espectáculo titulado Canto al trabajo de la compañía Pieles se estrenó en el Teatro Guimerá de Santa Cruz de Tenerife el día 26 de mayo de 2015. La actividad de la compañía puede seguirse a través de su página web: www.showpieles.com y de su facebook: www.facebook.com/showpieles. 
recrea la sonoridad popular de la música a través de una novedosa experiencia, en la que los recursos folclóricos del mundo más primitivo - la piedra, el cristal, la madera y el metal-alternan con instrumentos de corte clásico" (Rodríguez, 2016: 14).

Así pues, otro de los aspectos más destacables de este espectáculo es que, de alguna manera, ha permitido a los espectadores y críticos entender mejor y también profundizar más en algunos de los fundamentos rítmicos y sonoros de estas canciones asociadas al mundo del trabajo rural, pesquero o doméstico. ¿De dónde vienen unos y otros ritmos? ¿Con qué elementos del entorno pueden relacionarse tales o cuales sonidos? Si pensamos en las antiguas recolectoras, ¿ ¿no vendría marcado el ritmo de sus canciones por el choque de las semillas y la tierra contra el aro y la malla de la criba o el cedazo? O en aquellos hombres de la mar que iban a coger lapas, ¿no sería el rasgar de cuchillos contra la roca un elemento sonoro particularmente influyente en sus melodías? Por no hablar de los arrorrós que entonaban las madres canarias, ¿no estarían acompasados por el mecer de una cuna o un balancín?

Quince son las canciones en las que la compañía Pieles basó su espectáculo Canto al trabajo y que, por un lado, se presentan, describen y analizan en el libro Pieles: "Canto al trabajo" por Fátima Rodríguez y Jonatan Rodríguez y que, por otro, pueden escucharse y disfrutarse gracias al CD adjunto, editado por el sello discográfico Multitrack. Importante es también destacar su sugestivo Prólogo: "Canto al trabajo o el desafío de actuar lo popular”, elaborado por el profesor José Antonio Ramos Arteaga, especialista en teatro y literatura española medieval de la Universidad de La Laguna, quien concluye que Canto al trabajo es, sobre todo, "una respuesta esperanzada desde el arte a la pregunta de si todavía la tradición puede interpelarnos y si somos capaces — tú y yo, espectadoresde escuchar y apreciar desde sus lejanos ecos la herencia de dignidad, fraternidad y resistencia que nos ha legado en sus cantos" (Arteaga, 2016: 7).

La primera de estas piezas incluidas en el libro-CD es "Canto de las lavanderas", que en lo musical se sustenta en la melodía popular denominada "aires de Lima" (Ingenio, Gran Canaria), también conocida como "isa de la parida", pero cuya letra es de los mismos autores del libro: Fátima Rodríguez y Jonatan Rodríguez, quienes se inspiraron para su composición, no obstante, en una canción popular de las lavanderas de Yaracuy (Venezuela). Aquí es el chapoteo de las ropas sobre el agua que fluye entre las piedras lo que marca el ritmo de esta canción interpretada por las estupendas voces de las dos solistas femeninas: la propia Fátima Rodríguez y Laura Álvarez, acompañadas por el solista masculino, el tenor José Félix Álvarez, que "se une al canto mientras afila un cuchillo canario a la vieja usanza, con una piedra de amolar" (Rodríguez, 2016: 24)3). Y así, esos constantes sonidos percutidos de las ropas contra un agua que no para de

3. A este cuchillo canario de labranza se le conoce como naife o nife, que proviene del término inglés knife (Lorenzo, 1994: 235). 
fluir y del cuchillo contra una piedra de amolar que no detiene su permanente giro se convierten en una metáfora de la vida humana, en la que el transcurso imparable del tiempo se contrapone a nuestra recurrencia y fijación perceptiva a los recuerdos, en la que el presente donde estamos se ve condicionado por el pasado que nos dice quiénes somos o, mejor dicho, quiénes creemos ser: "Lavando estoy de rodillas / en las piedras del barranco / y vienen hasta mi orilla / los recuerdos del pasado" (Rodríguez, 2016: 25).

La segunda composición, "Arrau", no es ni más ni menos que una típica canción de cuna de la isla de El Hierro, un género musical este que en el conjunto de Canarias se conoce como arrorrót. Contamos, en este caso, con una letra y melodía populares, pero con arreglos de Jonatan Rodríguez y Jeremías Martín e interpretada por José Félix Álvarez, acompañado por la calidez del fliscorno de Germán G. Arias y el infalible piano de Jeremías Martín. Si hay un tipo de canción en la que todo el sentir de una madre o un padre - sus miedos, sus angustias, sus ilusiones, su amor...- por un hijo están presentes es esta: la canción de cuna, y particularmente el arrorró canario, a través del cual no sólo se protege al bebé en su tránsito de la vigilia al sueño, sino mediante el que se le da alivio cuando llega el desconsuelo: "No llores, mi niño chico, / no llores, que me das pena, / que la Virgen de los Reyes / tu tierno llanto consuela" (Rodríguez, 2016: 26).

El tercer tema, las "Seguidillas maxadas", es especialmente atractivo, sobre todo si tenemos en cuenta que la percusión del mismo, que proviene de unos morteros de los que hacen uso los cantantes solistas: Fátima Rodríguez, José Félix Álvarez y Laura Álvarez, "imitando su uso doméstico y golpeándolos rítmicamente" (Rodríguez, 2016: 28), y del choque de mazas contra un pilón que llevan a cabo los percusionistas de Pieles: Fede Beuster, Jonatan Rodríguez y Ventor de la Guardia, quienes, además, durante la actuación en el escenario "ejecutan una suerte de baile rítmico [...] al más puro estilo africano" (Rodríguez 2016: 28). Una gran elección escenográfica para la representación dramático-musical de esta canción cuya esencia está basada en las seguidillas de la isla de Fuerteventura o Maxorata (en guanche). La melodía y la letra populares de esta canción con arreglos de Jonatan Rodríguez son de tono jovial y festivo, producto de una mirada hedonista y alegre del amor y, por supuesto, de la vida en el campo, donde el duro trabajo deja sin embargo espacio también para el disfrute y el encuentro sentimental y erótico de los amantes, como así lo percibe el yo lírico cuando le dice socarronamente a la amada: "Cuando vienes del campo, / vienes airosa, / vienes coloradita / como una rosa", o, más pícaramente aún, cuando al amado le increpa: "Dices que no la quieres / ni vas a verla, / pero la veredita / no cría hierba" (Rodríguez, 2016: 29).

Muy distinto es el tono, en cambio, que tienen las "Seguidillas de la orilla" interpretadas por Fátima Rodríguez; un tema cuya letra es de Jonatan Rodríguez, quien, junto con

4. El término arrau es de origen bereber y significa 'niño/s' o 'niña/s'; según algunos dialectólogos, de esta palabra vendría el canarismo arrorró (Santana, 2015) 
Jeremías Martín, realizó igualmente los arreglos de esta melodía inspirada en las populares seguidillas manchegas de Tenerife. Temáticamente giran en torno los versos al paso del tiempo y a las pérdidas que este va ocasionando, entre ellas la de la juventud, pero también la de los propios recuerdos, cuya nitidez se va debilitando con el transcurrir de los años: "Veo en mis manos / barrancos que se apuran, / las sal y las arrugas / y tu eco lejano. // Tu eco lejano, / mis manos tan vacías, / mis manos tan vacías / y tu olor olvidado" (Rodríguez, 2016: 30).

Un particular interés tiene desde el punto de vista antropológico, lingüístico y cultural la canción "Silbo", que no es ni más ni menos que una "interpretación silbada de un poema que trata sobre la necesidad de comunicarse y el especial modo de hacerlo que existe en Canarias desde tiempos remotos a través del lenguaje silbado" (Rodríguez, 2016: 33), lenguaje que no solo se dio en La Gomera (Trujillo, 1978; Trujillo, 2006), sino, aunque con menor pervivencia, en otras islas como El Hierro (Trapero, 1991; Díaz Reyes, 2008). El poema al que se hace referencia es de Jonatan Rodríguez, quien termina su composición con estos tan elocuentes versos: "Porque, cuando hay algo que contar, / aquí, en mi tierra..., / la palabra se dice, / se silba / o se canta" (Rodríguez, 2016: 32), tres elementos que se conjugan en este tema donde la palabra poética y el silbo canario - ejecutado, por cierto, por Guillermo Molina - se aúnan en un mismo canto.

Y del silbo que se utilizaba en el interior de algunas de nuestras islas para comunicarse entre montañas, nos desplazamos ahora a la costa gracias al precioso tema "Morenita", una composición íntegramente realizada por el grupo Pieles, aunque inspirada en el ancestral "canto de la morena" que muchos de los pescadores de esta especie han empleado y siguen empleando en nuestras islas. La función de este canto es múltiple: por una parte, la de "atraer al citado pez y dejarlo aletargado" (Rodríguez, 2016: 39), pero también, por otra, la de carácter ritual que promueve la concentración y la suerte del pescador en una faena complicada y arriesgada, pues sin duda es peligrosa la morena y difícil de pescar. De este tema de letra popular con arreglos de Jonatan Rodríguez conviene destacar su música, compuesta por Fátima Rodríguez, que profundiza en los tonos y los ritmos de los cantos tradicionales para recrearlos de una manera innovadora y tremendamente llamativa. Acompañados por el piano de Jeremías Martín, los tres cantantes solistas y los percusionistas marcan el compás de la canción con calabazas de agua, que rellenas de algún material percusivo suelen usarse aquí en Canarias como instrumentos de percusión de la familia de los idiófonos ${ }^{5}$.

5. Dos famosas composiciones musicales previas relacionadas temáticamente con el "canto de la morena" fueron "El pescador de morenas" del grupo tinerfeño Los Sabandeños (en A la luz de la luna, 1990) y "El canto de la morena" del grupo grancanario Artenara (en Artenara, 1998), del cual fue fundador, por cierto, Germán G. Arias, miembro actualmente de la compañía Pieles. 
Mucho éxito entre el público ha tenido la canción "Campesina", una adaptación con arreglos melódicos de Jonatan Rodríguez y Jeremías Martín y letrísticos de Laura Álvarez Izquierdo de "La saranda", tema popular del folclorista lanzaroteño Juan Brito (Tinajo, 1919). Como en otras composiciones anteriores, parte de la instrumentación de esta se vincula claramente al proyecto de Pieles de reutilizar los sonidos propios del mundo del trabajo dotándolos de un sentido musical. Así pues, aquí "se emplean zarandas con grano en su interior a modo de instrumento de percusión" (Rodríguez, 2016: 41). Un canto es este destinado a reivindicar la labor de tantas generaciones de sembradoras y cosecheras que, con su trabajo de sol a sol en el campo, nos han facilitado el alimento al pueblo: "Acaricia, campesina, / con tus manos todo el grano, / para que ofrezcas al mundo, / de la tierra, tu legado" (Rodríguez, 2016: 40).

Relacionada con "Campesina" está la "Danza del trigo", gran reinterpretación de Pieles de la canción popular palmera conocida como "Cho Juan Periñal", un canto de trabajo vinculado con los cultivadores de trigo palmeros. Este tema adquiereuna especial significación en su puesta en escena, cuando los músicos y los cantantes participan juntos en la representación del "proceso del cultivo del trigo, desde su siembra hasta su recolección e ingesta como pan” (Rodríguez, 2016: 42). Además, los percusionistas en esta canción marcan el ritmo de la melodía mediante el golpeo con grandes mazas de un dornajo, "siguiendo una costumbre indonesia para separar el grano de arroz de la cáscara" (Rodríguez 2016: 42), hecho que patentiza, asimismo, el carácter multicultural de Canto al trabajo, pues, en el fondo, y al margen de las diversas técnicas que se puedan emplear en las diferentes culturas, ¿no sienten y padecen internamente los mismos pesares y alegrías, los mismos anhelos y esfuerzos, todos los agricultores del mundo? ¿No es acaso la misma la tierra sobre la que siembran y recogen sus frutos? Tal y como el prologuista del libro-CD plantea: "Este es uno de los principales logros de Pieles, reivindicar la radical autonomía de lo popular de un grupo humano concreto y proclamar el universalismo del canto y la performance tradicional" (Ramos, 2016: 6).

En esta misma línea multicultural se sitúa "Ánimas", un potente tema abierto al misterio, cuya música y letra populares fueron arregladas por Jonatan Rodríguez y puestas en relación melódica con la canción portuguesa de Beira Baixa "Senhora do Almortão". La canción de Pieles se inspira en la tradición folclórico-religiosa desarrollada en el barrio rural de Arbejales, perteneciente al municipio grancanario de Teror y donde se celebran los denominados "ranchos de ánimas", esto es, la organización de "grupos de personas que se reúnen para cantar y tocar con la intención de recaudar dinero para costear misas por las almas de los difuntos" (Rodríguez, 2016: 45). Una de las curiosidades musicales de este tema es que para representar el repicar de campanas de una iglesia se golpean grandes garrafones de cristal. Esta canción con valores rituales, además de una función meramente recaudatoria, destina su contenido a apelar al poder divino con el objetivo 
de que este procure el bienestar definitivo y la paz última de las almas de los muertos: "Ánimas, ánimas que están en pena, / en aquella oscuridad, / el señor las saque de ella. / El señor las saque de ella / y las lleve a descansar / donde más descanso tengan” (Rodríguez, 2016: 44).

Confluyen la siguiente canción, "Romance", también varias y diversas combinaciones de aspectos: por un lado, un romance del poeta canario Pedro García Cabrera (Vallehermoso, La Gomera, 1905 - Santa Cruz de Tenerife, 1981) musicalizado como un tajaraste, melodía folclórica canaria, y, por otro lado, los ritmos y sonidos propios de la música popular de nuestras islas en paralelo con "una sonoridad brasileña a partir del toque de un tambor llamado rebolo a ritmo de samba" (Rodríguez, 2016: 50). Aceptar nuestros orígenes geográficos, culturales y familiares y reconocerlos como parte fundamental de nuestra identidad individual y colectiva, labrada en gran medida durante nuestra niñez, es lo que parecen proponernos estos versos cantados magistralmente por el solista José Félix Álvarez: "A cara o cruz he lanzado / a la mar una moneda; // salió cuna y nací yo: / cuna o concha es La Gomera. // Súbete al roque más alto, / silba con todas tus fuerzas // hacia atrás, hacia la infancia, / a ver si el eco recuerda // las bordadas camisillas / que abrigaron mi inocencia" (Rodríguez, 2016: 51).

No podía faltar en una obra como Canto al trabajo un género tan importante en el folclore musical canario como la folía, cuya génesis, no obstante, hunde sus raíces en la cultura portuguesa, de donde proviene también el término magua, que el Diccionario de canarismos define como "pena, lástima, desconsuelo por la falta, pérdida o añoranza de algo o por no haber hecho algo que hubiera redundado en beneficio propio" (Lorenzo, 1994: 210). En este tema titulado "Folías de la magua", el yo lírico lamenta y llora la ausencia de un ser querido: "Lágrimas que van al mar / a encontrarse con tu estela, / es lo único que me queda, / así que vuelvo a cantar” (Rodríguez, 2016: 52). La letra de esta folía es obra de Fátima Rodríguez, una de las cantantes que interpreta la canción y que se acompaña para ello de un timple, instrumento esencial en la música popular canaria que, dicho sea de paso, famosos timplistas como Luis Millares Sall: Totoyo, Benito Cabrera, el ya fallecido José Antonio Ramos o Domingo Rodríguez el Coloraohan sabido reivindicar con sus composiciones como instrumento solista de amplias posibilidades melódicas como lo son otros instrumentos cordófonos como, sin ir más lejos, la guitarra.

Al igual que la primera pieza incluida en este libro-CD, también "Tijarafe" se fundamenta desde el punto de vista musical en la melodía popular "aires de Lima", pero si bien en aquel caso lo hacía en su modalidad grancanaria, lo hace en este en su vertiente palmera. Es relevante en este tema la fusión entre lo folclórico y lo clásico gracias a la mezcla de instrumentos tan diferentes como el violonchelo de Ciro Hernández, el contrabajo de Juan Antonio Mora, el piano de Jeremías Martín, la trompa de Germán G. Arias y los tambores canarios de Jonatan Rodríguez, Fede Beuster y Ventor de la Guardia, así como 
la utilización de un tempo un tanto más pausado que convierte esta canción popular y de tipo festivo en una auténtica balada de corte contemporáneo; una combinación de elementos escénicos, sonoros, rítmicos e instrumentales que el investigador José Antonio Ramos Arteaga (2016: 6) entra a analizar en su prólogo considerándola, al igual que nosotros, un acierto estético:

"Es muy fácil desde el campo académico, armado con bibliografías y metodologías, pontificar por medio de baremos teóricos sobre lo que es tradicional o no, quién es más puro, o si una fusión es admisible o, por el contrario, se trata de una traición imperdonable. Pero ¿y el artista que desde un saber orgánico y herramientas tanto intelectuales como intuitivas se enfrenta a la necesidad de transmitir esta tradición? ¿Cómo evitar el efecto museo que agosta la performance popular en un catafalco funerario? (...)

Canto al trabajo es un admirable ejemplo de respuesta a estos interrogantes".

El siguiente tema, que en el espectáculo va ligado al anterior, es "Tajaraste del tambor", una adaptación del tajaraste, género folclórico canario de especial difusión en La Gomera, donde se le llama también "Baile del tambor"; y así, como no podía ser de otra manera, predominan en esta canción instrumentos como los tambores, por supuesto, pero también las chácaras y el silbo gomero, además de terminar con el zaghareet, grito ritual norteafricano bien conocido en Canarias gracias, sobre todo, a nuestras históricas relaciones con el pueblo saharaui, y que, por ejemplo, ha sido usado igualmente con fines musicales por el célebre grupo palmero Taburiente en varias de sus canciones. La letra de "Tajaraste del tambor" es obra de Jonatan Rodríguez y está integrada por diferentes estrofas sobre tres deportes autóctonos de Canarias: la lucha canaria, el juego del palo y el salto del pastor, al que se le dedican los siguientes versos: "Pasa el pastor con el regatón / sobrevolando el monte, / posa la lanza en la tierra, / la mirada en el horizonte" (Rodríguez, 2016: 57).

"Meda, la canción que sigue, está basada musicalmente en el género folclórico del mismo nombre y de particular desarrollo en la isla de El Hierro, donde se emplea para musicalizar los romances populares, de manera similar a lo que ocurre en La Gomera, como veíamos antes, con el tajaraste. Como la propia compañía Pieles sostiene, "esta práctica musical tradicional está estrechamente relacionada con las faenas agrícolas, ganaderas y pesqueras" (Rodríguez, 2016: 58), de ahí la importancia de este tema en el conjunto de Canto al trabajo. Asimismo, de nuevo nos encontramos aquí con una innovadora fusión de ritmos y sonidos a través de la cual se pone de relieve, entre otras cosas, la eficacia de los arreglos melódicos de Jonatan Rodríguez y la sintonía y el equilibrio de las tres voces solistas, dando lugar a un tema de auténtica raíz popular canaria, pero con tonalidades y tintes propios de músicas como el góspel, lo que casa fácilmente con la letra de "Meda": 
"Al pie de la cruz, María, / sale el sol y rompe el día. // Vamos a cantar la meda, / estaremos todo el día” (Rodríguez, 2016: 58).

Termina el libro-CD con la pieza titulada "Duque de Gha-Bras", inspirada en el romance popular grancanario "Duque de Cabra", del que se recoge un fragmento de su letra. El cambio de título responde "a un juego de palabras con el término gha, denominación que recibe la nota musical do en la música indostánica y que se corresponde con el balido de la cabra" (Rodríguez 2016: 61). Los arreglos musicales de Jonatan Rodríguez y Fátima Rodríguez vienen marcados, en este tema, por las influencias rítmico-melódicas árabes y por la incorporación de instrumentos de otras culturas como los krakebs, especie de castañuelas metálicas de tradición marroquí, y un darbuka egipcio. Una canción en la que, con cierto tono humorístico, se presenta el conflicto entre las clases populares, trabajadoras, y los nobles y terratenientes, aunque en este caso por confusas cuestiones amorosas: "Me coge en el barranco, / donde la piedra labra, / dice el duque de Cabra: / «la viuda es para mí». // [...] Ay, triste de mí, / que yo te quiero a ti, / yo no quiero a la viuda, / ay, triste de mí" (Rodríguez, 2016: 60).

Al hablar del espectáculo del grupo Pieles desde el punto de vista del espectador, es inevitable que en un primer momento afloren los argumentos emocionales que vinculan la propuesta artística con las experiencias individuales, en su dimensión tanto biográfica como colectiva, esto es, la voz familiar o la voz del pueblo, el alma individual o el alma colectiva. Tristeza, regocijo, alegría, esfuerzo, trabajo; todo ello se entreteje en un diálogo silencioso que propicia el espectáculo, y que, desde el canto, la recreación artística o la interpretación musical van labrando una voz que despierta en el espectador algo que es muy difícil de atrapar intelectual y estéticamente, al menos a posteriori: la belleza. En unos casos se resalta la forma o el contenido, lo musical, lo poético, lo folclórico. No resulta indiferente como propuesta artística. Tal vez el éxito emocional, que a la postre es la primera valoración que hace el público, tenga que ver con algo sutil del espectáculo: el juego con los límites. Antoni Tàpies sabía de esta sencilla transgresión al exponer una silla como objeto artístico. René Magritte nos advertía con su cuadro "Ceci n’estpas une pipe" ("Esto no es una pipa") sobre lo que estábamos viendo: ¿una pipa?, ¿una imagen de una pipa?, ¿tal vez todas las pipas? Es evidente que Canto al trabajo es música, teatro, performance, folclore, tradición, modernidad, fusión y se sitúa siempre en la frontera de lo que es o lo que podría ser, parece que nunca se decanta; es el espectador el que tiene que hacer inclinar la balanza hacia el lugar que estime oportuno. Es muy difícil categorizarlo. Mallarmé hablaba sobre la rosa diciendo que era "l'absence de toute rose" ("la ausencia de toda rosa") y parece que en este caso es difícil también separar individualmente los elementos de la representación, hecho que reafirma su incuestionable éxito y calidad, que basculan íntimamente unidos. Toda buena propuesta artística plantea un juego estético y en este caso lo hay. En Dogville y Manderlay, del cineasta Lars von Trier, se juega 
con los límites del teatro y el cine y en ningún caso vemos que haya una decantación deliberada sobre un género u otro. La que sale reforzada es la ejecución de los actores, y somos nosotros, los espectadores, los que vemos que estamos ante algo inusual que exige dotes interpretativas para valorar una propuesta con cierto riesgo. Pieles logra el mismo efecto: potencia las características de cada estilo que conforma Canto al trabajo de manera sobresaliente y sin decantarse en realidad por ninguno de ellos. Cada uno que vio el espectáculo asumió que estaba ante algo novedoso, inusual, y fue en la recepción del mismo que se destacó el papel interpretativo de toda la representación, y, por tanto, se potenció su valor folclórico, musical, teatral, etcétera, no como algo encapsulado y dirigido con anterioridad, si no como algo nuevo y vivo.

Otros miembros y colaboradores de la compañía Pieles que han hecho posible la realización del espectáculo multidisciplinar Canto al trabajo y, por consiguiente, del magnífico libro-CD han sido el videocreador y diseñador de iluminación Dimas Cedrés, el ingeniero y diseñador de sonido Ubaldo Pérez, el responsable del área educativa del proyecto Oswaldo Bordón, los fotógrafos Raúl Santana, Fonsi Martín, Carlos Prieto y Nacho González Oramas y los productores musicales Agustín Mesa (mezclas) y Mario G. Alberni (masterización). 


\section{REFERENCIAS BIBLIOGRÁFICAS}

Díaz Reyes, David (2008) El lenguaje silbado en la isla de El Hierro. El Hierro: Ediciones del Cabildo de El Hierro.

Lorenzo, A.; Morera, M. y Ortega, G. (1994) Diccionario de Canarismos. Tenerife: Francisco Lemus.

Ramos Arteaga, José Antonio (2016) "Canto al trabajo o el desafío de actuar lo popular". En Fátima Rodríguez y Jonatan Rodríguez, Pieles: “Canto al trabajo". Tenerife: Factoriadelarte, pp. 5-7.

Rodríguez, Fátima y Rodríguez, Jonatan (2016) Pieles: "Canto al trabajo" (libro-CD). Traducción de Marta Aubín, versión bilingüe español/inglés. Tenerife: Factoriadelarte.

Santana, Ana (2015) "El arrorró, una antigua canción de cuna bereber que llegó a España y América”. Disponible en: http://web.eldia.es/2015-04-07/cultura/cultura3.htm [Consultado el 11 de abril de 2017].

Trapero, Maximiano (1991) "Lenguaje silbado en El Hierro".La Provincia 7 nov. 1991. Disponible en: http://www.webs.ulpgc.es/canatlantico/pdf/otros/Lenguaje_silbado.pdf [Consultado el 19 de abril de 2017].

Trujillo, Ramón (1978) El silbo gomero. Análisis lingüistico. Tenerife: Interinsular Canaria. Trujillo, Ramón (2006) El silbo gomero. Nuevo estudio fonológico. Gran Canaria: Ediciones de la Academia Canaria de la Lengua. 